\title{
Effect of Temperature on HTO-Dissociation Determined by Ion Exchange Resins
}

\author{
Naoki Kano, Daisuke Arai and Hiroshi ImaIzumi \\ Department of Chemistry and Chemical Engineering, Faculty of Engineering, Niigata University, \\ Ikarashi, Niigata 950-2181, Japan
}

\begin{abstract}
In order to reveal the effect of temperature on (i) the dissociation equilibrium of tritiated water (HTO water) and (ii) the reactivity of each anion-exchange resin, the OT-for-OH exchange reaction between each anion-exchange resin and HTO water was studied within the range of $20^{\circ} \mathrm{C}$ to $80^{\circ} \mathrm{C}$ in the equilibrium state. In addition, the apparent dissociation constant $\left(\mathrm{p} K^{\prime}\right)$ for each resin was estimated by the method of $\mathrm{pH}$-titration. From the observation of the OT-for-OH exchange reaction between each of the following anion-exchange resins and HTO water, the next three items have been found: (1) in the case of acryl-type anion-exchange resin, the effect of temperature on OT-for-OH exchange reaction is larger than that on the reaction in the case of styrene-type one; (2) the radioactivity incorporated into weakly basic anion-exchange resin $\left(\mathrm{OH}^{-}\right.$-form $)$by the isotope exchange reaction is smaller than that into strongly basic one; (3) in the case of the weakly basic anion-exchange resin, the amount of radioactivity incorporated into $\mathrm{Cl}^{-}$-form resin by the hydrolysis is larger than the amount of radioactivity incorporated into $\mathrm{OH}^{-}$-form resin by the isotope exchange reaction.
\end{abstract}

Keywords OT-for-OH exchange reaction, anion-exchange resin, tritium, dissociation of tritiated water, apparent dissociation constant

The external exposure from $\mathrm{T}$ can be neglected because (1) the half-life of the tritium (T) is relatively long $(12.3 \mathrm{y})$, and (2) the maximum energy of the $\beta^{-}$rays emitted from $\mathrm{T}$ is relatively low $(18.6 \mathrm{keV})$. When $\mathrm{T}$ is incorporated into the body, it can be thought that $\mathrm{T}$ causes some internal exposure, and is exchanged with ${ }^{1} \mathrm{H}$ in important functional groups in the body. ${ }^{1,2}$ The $\mathrm{T}$ concentration in the atmosphere increases with increasing the number of nuclear power plants and reprocessing plants for spent nuclear fuel, and with the further study of nuclear fusion. ${ }^{2}$

We have studied the hydrogen-isotope exchange reactions (T-for-H exchange reactions) between T-labeled compounds and unlabeled ones having a functional group in gas-solid ${ }^{2,3}$ and liquid-solid ${ }^{2,4,5}$ systems. Moreover, several isotope exchange reactions between T-including atomic groups (i.e., OT-for-OH exchange reactions) were recently observed in the equilibrium state. $^{6-8}$ The following have been found: (1) OT-for-OH exchange reaction occurred between HTO water and each strongly basic anion-exchange resin having styrene-divinylbenzene copolymer matrix; (2) the higher the temperature is, the smaller is the radioactivity due to OT-for-OH exchange reaction in anion-exchange resin (IRA400), and the higher the temperature is, the larger is the radioactivity due to T-for-H exchange one in the case of cation-exchange resin (IR120B); (3) the radioactivity of the resin due to exchange reaction decreases with increasing the degree of crosslinking.

$\mathrm{HTO}$ and $\mathrm{ROH}$ (where $\mathrm{ROH}$ means each $\mathrm{OH}^{-}$-form anion-exchange resin) dissociate as shown in Formulas (1), (2), and (3), respectively.

$$
\begin{aligned}
& \mathrm{HTO} \rightleftharpoons \mathrm{H}^{+}+\mathrm{OT}^{-} \\
& \mathrm{HTO} \rightleftharpoons \mathrm{T}^{+}+\mathrm{OH}^{-} \\
& \mathrm{ROH} \rightleftharpoons \mathrm{R}^{+}+\mathrm{OH}^{-}
\end{aligned}
$$

Consequently, the OT-for-OH exchange reaction between HTO and ROH can be expressed as Formula (4).

$$
\mathrm{ROH}+\mathrm{HTO} \rightleftharpoons \mathrm{ROT}+\mathrm{H}_{2} \mathrm{O}
$$

When the $\mathrm{H}^{+}$-form cation-exchange resin is abbreviated as $\mathrm{R}^{\prime} \mathrm{H}$, the T-for-H exchange reaction between HTO and $\mathrm{R}^{\prime} \mathrm{H}$ can be expressed as Formula (5).

$$
\mathrm{R}^{\prime} \mathrm{H}+\mathrm{HTO} \rightleftharpoons \mathrm{R}^{\prime} \mathrm{T}+\mathrm{H}_{2} \mathrm{O}
$$

Based on the above-mentioned, we aimed in this work to clarify (1) the behavior of $\mathrm{T}$ when tritiated water (HTO water) dissociates, (2) the effect of temperature on the dissociation equilibrium of HTO water, (3) the effect of temperature on the reactivity of each anion-exchange resin, and (4) the effect of the matrix of each anion-exchange resin on the reactivity of the resin. 


\section{Experimental}

\section{Sample material}

Anion-exchange resins used were Amberlite IRA400 (strongly basic styrene type) which has quaternary ammonium salt as a functional group, IRA458 (strongly basic acryl type) having the same functional group as IRA400, and IRA96SB (weakly basic styrene type) having tertiary amine as a functional group. The cation-exchange resin used for comparison was Amberlite IR120B having sulfonate as a functional group (strongly acid styrene type). The structure of the functional group in each ion-exchange resin is shown in Fig. 1. HTO water (specific radioactivity: $185 \mathrm{MBq}$ $\mathrm{g}^{-1}$ ) was purchased from Japan Radioisotope Association (JRIA), and was diluted to $0.9 \mathrm{MBq} \mathrm{g}^{-1}$ in this experiment. The specific radioactivity of HTO water thus prepared was precisely measured with a liquid scintillation counter (Aloka LSC-5101).

\section{Isotope exchange reaction}

The experimental procedure for isotope exchange reaction is generally the same as that mentioned before. ${ }^{8}$ The method can be summarized as follows. (1) About $60 \mathrm{mg}$ of each regenerated resin was placed in a vial. (2) After $0.300 \mathrm{~cm}^{3}$ of HTO water was added into the vial, the vial was shaken for $1 \mathrm{~h}$. (3) After that, the vial was vacuum-dehydrated for $3 \mathrm{~h}$ by using a vacuum line. (4) An aliquot of the resin (ca. $20 \mathrm{mg}$ ) was placed into another vial, and was weighed precisely. (5) In case of each anion-exchange resin, $5.00 \mathrm{~cm}^{3}$ of $1 \mathrm{~mol}$ $\mathrm{dm}^{-3} \mathrm{HCl}$ was added to the vial. In case of the cationexchange resin, $0.5 \mathrm{~mol} \mathrm{dm} \mathrm{dm}^{-3} \mathrm{NaOH}$ solution was used instead of $1 \mathrm{~mol} \mathrm{dm}^{-3} \mathrm{HCl}$ solution. In case of a weakly anion-exchange resin, $5.00 \mathrm{~cm}^{3}$ of organic solvent was added to the vial, and the vial was vacuum-dehydrated for $3 \mathrm{~h}$; then $5.00 \mathrm{~cm}^{3}$ of $1 \mathrm{~mol} \mathrm{dm}^{-3} \mathrm{HCl}$ was added. (6) The resin in each vial was filtered out. (7) The radioactivity of $1.00 \mathrm{~cm}^{3}$ of the filtrate was measured with a liquid scintillation counter.

\section{pH-titration curve}

The procedure for making a $\mathrm{pH}$-titration curve was as follows. (1) Each regenerated anion-exchange resin (ca. $0.5 \mathrm{~g}$ ) was weighed precisely, and put into a vessel (500 $\mathrm{cm}^{3}$ ) with $200 \mathrm{~cm}^{3}$ distilled and $\mathrm{CO}_{2}$-free water. (2) $\mathrm{A}$ $\mathrm{pH}$ electrode (HORIBA 6366-10D) and a buret for dropping the titrant $\left(0.100 \mathrm{~mol} \mathrm{dm}^{-3} \mathrm{HCl}\right)$ were set into the vessel. (3) After the solution was degassed with nitrogen, the $\mathrm{HCl}$ solution was dropped into the vessel in a nitrogen atmosphere. In case of Amberlite IR120B, the titrant was $0.100 \mathrm{~mol} \mathrm{dm}^{-3} \mathrm{KOH}$. The $\mathrm{pH}$ value of the solution was measured with a $\mathrm{pH}$ meter (HORIBA F-13) when the proper amount of the titrant was added to reach an equilibrium. The procedure for measuring total ion-exchange capacity was generally based on the literature. ${ }^{10,11}$
(1) Anion-exchange resin

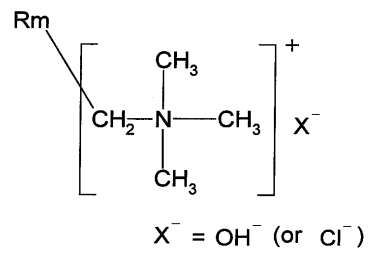

Amberlite IRA400 (Styrenic matrix) Amberlite IRA458 (Acrylic matrix)

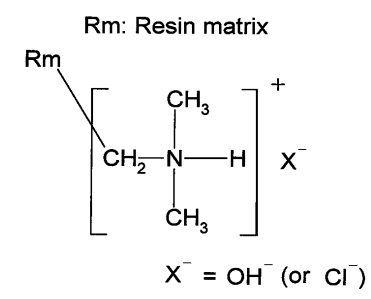

Amberlite IRA96SB (Styrenic matrix)

(2) Cation-exchange resin

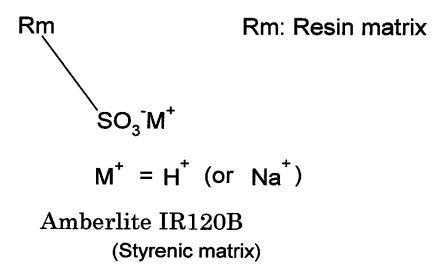

Fig. 1 The structure of the functional group in each ionexchange resin used.

\section{Results and Discussion}

Determination of the apparent dissociation constant for each resin

In order to investigate the effect of the ionic dissociation of the resin on the isotope exchange reaction, an apparent dissociation constant $\left(\mathrm{p} K^{\prime}\right)^{11-13}$ was estimated for each resin. Although $\mathrm{p} K^{\prime}$ is different from $\mathrm{p} K$ (which represents the strength of acid-base), it is an useful indication for estimating the degree of the dissociation in each ion-exchange resin.

Based on the following dissociation equilibrium in the resin phase (Formula (6)), the $\mathrm{p} K_{\mathrm{a}}^{\prime}$ value for each cationexchange resin $\left(\mathrm{R}^{\prime} \mathrm{H}\right)$ can be estimated as follows. ${ }^{11-13}$

$$
\begin{aligned}
& \mathrm{R}^{\prime} \mathrm{H} \rightleftharpoons \mathrm{R}^{\prime}-+\mathrm{H}^{+} \\
& K_{\mathrm{a}}^{\prime}=\frac{\left[\mathrm{R}^{\prime}-\right]\left[\mathrm{H}^{+}\right]}{\left[\mathrm{R}^{\prime} \mathrm{H}\right]}, \mathrm{p} K_{\mathrm{a}}^{\prime}=-\log K_{\mathrm{a}}^{\prime} \\
& \mathrm{p} K_{\mathrm{a}}^{\prime}=\mathrm{pH} H^{0}+\log \left[\mathrm{K}^{0}\right]-\log \left[\mathrm{X}^{0} / 2\right]
\end{aligned}
$$

where $\left[\mathrm{X}^{0}\right]$ is the concentration of the functional group in the resin, which is determined from the end point value of the $\mathrm{KOH}$ titration and is equal to the total ionexchange capacity. ${ }^{11}$ Here $\mathrm{pH}^{0}$ and $\left[\mathrm{K}^{0}\right]$ are the $\mathrm{pH}$ and the $\mathrm{KOH}$ concentration at half-volume point of the titration, where half the volume of $\mathrm{KOH}$ titrant has been added to the solution.

Similarly, in case of anion-exchange resin $(\mathrm{ROH})$, based on the dissociation constant, the $\mathrm{p} K_{\mathrm{b}}{ }^{\prime}$ value is calculated as follows using the autoprotolysis constant $\left(K_{\mathrm{w}}\right)$ for $\mathrm{H}_{2} \mathrm{O}$ :

$$
K_{\mathrm{b}}^{\prime}=\frac{\left[\mathrm{R}^{+}\right]\left[\mathrm{H}^{-}\right]}{[\mathrm{ROH}]}, \mathrm{p} K_{\mathrm{b}}^{\prime}=-\log K_{\mathrm{b}}{ }^{\prime}
$$




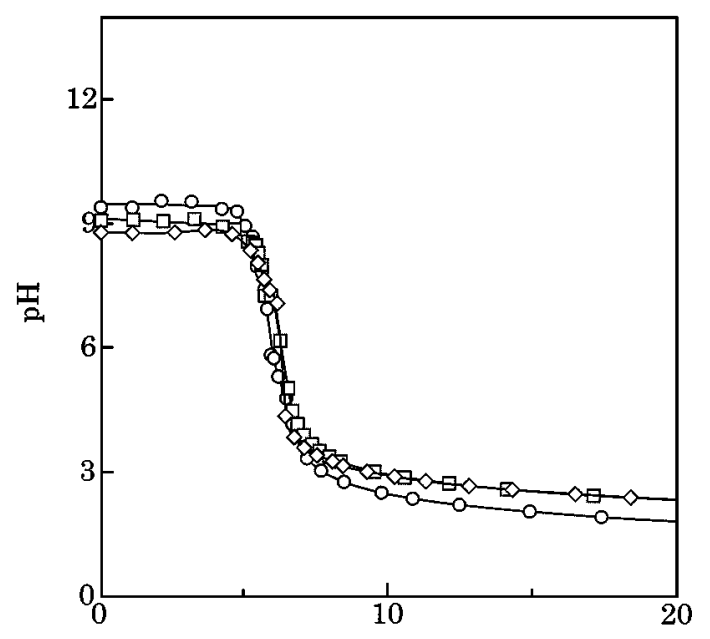

Amount of $0.100 \mathrm{~mol} \mathrm{dm}^{-3} \mathrm{HCl} / \mathrm{cm}^{3}$

Fig. 2 pH-titration curves for IRA400. $\circ: 20^{\circ} \mathrm{C} ; \square: 40^{\circ} \mathrm{C} ; \diamond$ : $60^{\circ} \mathrm{C}$.

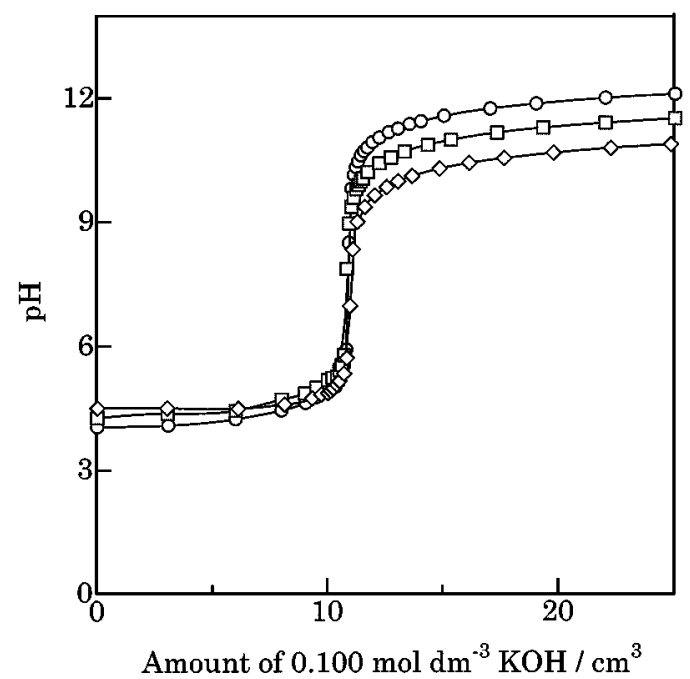

Fig. 3 pH-titration curves for IR120B. $\circ: 20^{\circ} \mathrm{C} ; \square: 40^{\circ} \mathrm{C}$; $\diamond$ : $60^{\circ} \mathrm{C}$.

$$
\mathrm{p} K_{\mathrm{b}}{ }^{\prime}=-\log K_{\mathrm{w}}-\mathrm{pH} \mathrm{H}^{0}+\log \left[\mathrm{Cl}^{0}\right]-\log \left[\mathrm{X}^{0} / 2\right]
$$

where $\left[\mathrm{X}^{0}\right]$ is the concentration of the functional group in the resin, which is determined from the end point value of the $\mathrm{HCl}$ titration and is equal to the total ionexchange capacity. Here $\mathrm{pH}^{0}$ and $\left[\mathrm{Cl}^{0}\right]$ are the $\mathrm{pH}$ and the $\mathrm{HCl}$ concentration at half-volume point of the titration, where half the volume of $\mathrm{HCl}$ titrant is added to the solution.

The pH-titration curves for IRA400 and IR120B are shown in Figs. 2 and 3, and the total ion-exchange capacity for each resin is shown in Table 1. From these values, $\mathrm{p} K^{\prime}$ values for the resins were calculated using Eq. (8) or (10), as shown in Table 2. The $\mathrm{p} K_{\mathrm{b}}{ }^{\prime}$ value for IRA96SB is also calculated at each temperature (Table 2) by using the $\mathrm{pH}$-titration curve, total ion-exchange capacity (Table 1) and Eq. (10).
Table 1 Total ion-exchange capacity of each ion exchange resin at several temperatures

\begin{tabular}{cccc}
\hline \multirow{2}{*}{ Temperature $/{ }^{\circ} \mathrm{C}$} & \multicolumn{3}{c}{ Total ion-exchange capacity $/ \mathrm{mmol} \mathrm{g}^{-1}$} \\
\cline { 2 - 4 } & IRA400 & IRA96SB & IR120B \\
\hline 20 & 1.97 & 2.24 & 2.35 \\
40 & 1.91 & 2.36 & 2.35 \\
60 & 1.94 & 2.43 & 2.31 \\
\hline
\end{tabular}

Table 2 The $\mathrm{p} K^{\prime}$ value for each resin

\begin{tabular}{ccccc}
\hline \multirow{2}{*}{ Temperature/ ${ }^{\circ} \mathrm{C}$} & \multicolumn{2}{c}{$\mathrm{p} K_{\mathrm{b}}{ }^{\prime}$} & & $\mathrm{p} K_{\mathrm{a}}{ }^{\prime}$ \\
\cline { 2 - 3 } \cline { 5 - 5 } & IRA400 & IRA96SB & & IR120B \\
\hline 20 & 4.5 & 10 & \\
40 & 4.3 & 9.6 & \\
60 & 4.0 & 9.2 & \\
\hline
\end{tabular}

\section{Estimation of the adsorbed water in each resin}

In general, it is difficult to remove the moisture adsorbed in the interior of an ion-exchange resin completely because the resin is porous. ${ }^{9}$ Accordingly, the radioactivity obtained from each ion-exchange resin includes both the radioactivity adsorbed as HTO water and the radioactivity of $\mathrm{OT}^{-}\left(\right.$and $\left.\mathrm{T}^{+}\right)$exchanged with $\mathrm{X}^{-}\left(\right.$and $\mathrm{M}^{+}$) in the resins shown in Fig. 1 .

It is thought that the hydrolyses of $\mathrm{Cl}^{-}$-form of IRA400, $\mathrm{Cl}^{-}$-form of IRA458, and $\mathrm{Na}^{+}$-form of IR120B do not occur, but $\mathrm{Cl}^{-}$-form of IRA96SB causes hydrolysis, because the former are strongly basic (and acidic) types and the latter is weakly basic type.

Therefore, in case of IRA458, the real radioactivity incorporated into each resin by exchange reaction was estimated by subtracting the radioactivity adsorbed in the $\mathrm{Cl}^{-}$-form resin from the radioactivity in the $\mathrm{OH}^{-}$form resin as in the case of IRA400. ${ }^{8}$ On the other hand, in the case of IRA96SB, another estimation method using each organic solvent was applied. As for the results for IRA458 and IRA96SB, see the latter sections.

Effect of temperature on the dissociation equilibrium of HTO water

Using the data in Table 2, we normalized the $K^{\prime}$ values at $40^{\circ} \mathrm{C}$ and $60^{\circ} \mathrm{C}$ for IRA400 (or IR120B) to that at $20^{\circ} \mathrm{C}$.

$$
\begin{aligned}
& \text { IRA400 }\left(20^{\circ} \mathrm{C}\right):\left(40^{\circ} \mathrm{C}\right):\left(60^{\circ} \mathrm{C}\right)=1.0: 1.6: 3.2 \\
& \text { IR120B }\left(20^{\circ} \mathrm{C}\right):\left(40^{\circ} \mathrm{C}\right):\left(60^{\circ} \mathrm{C}\right)=1.0: 0.63: 0.63
\end{aligned}
$$

Further, the temperature dependence of the ratios of radioactivity incorporated into IRA400 (or IR120B) was obtained by using the data in Ref.8.

$$
\text { IRA400 }\left(20^{\circ} \mathrm{C}\right):\left(40^{\circ} \mathrm{C}\right):\left(60^{\circ} \mathrm{C}\right)=1.0: 1.1: 0.77
$$




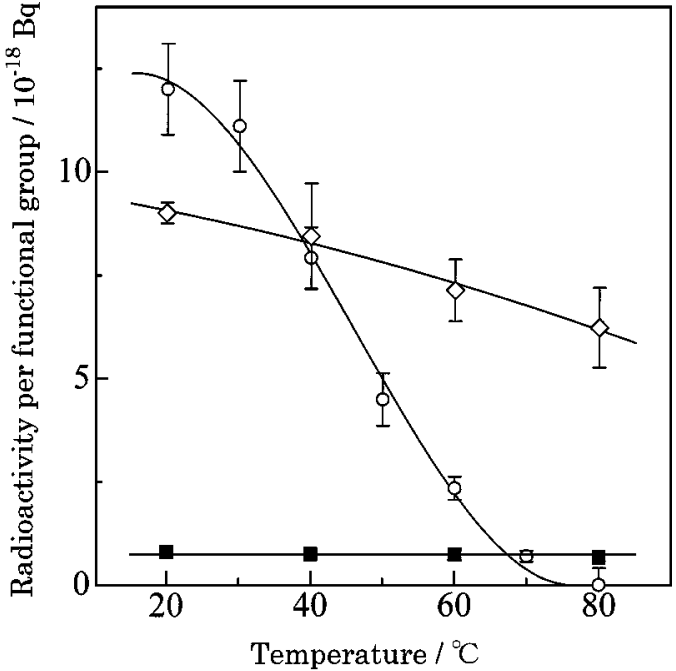

Fig. 4 Radioactivity per functional group in IRA458 (and IRA96SB) vs. temperature. o: IRA458; $\mathbf{~ : ~ I R A 9 6 S B ~}\left(\mathrm{OH}^{-}\right.$ form); $\diamond$ : IRA96SB $\left(\mathrm{Cl}^{-}\right.$-form).

$$
\text { IR120B }\left(20^{\circ} \mathrm{C}\right):\left(40^{\circ} \mathrm{C}\right):\left(60^{\circ} \mathrm{C}\right)=1.0: 1.5: 1.7
$$

In the case of IRA400, when the temperature rises from $20^{\circ} \mathrm{C}$ to $60^{\circ} \mathrm{C}$, the dissociation of IRA400 increases by a factor of 3.2 , while the radioactivity in the OT-for-OH exchange reaction becomes 0.77 times. Then, the decreasing rate of "HTO $\rightleftharpoons \mathrm{H}^{+}+\mathrm{OT}^{-}$" is estimated to be $0.24(0.77 \times 1.0 / 3.2)$ if one raises the temperature from $20^{\circ} \mathrm{C}$ to $60^{\circ} \mathrm{C}$.

In case of IR120B, when the temperature rises from $20^{\circ} \mathrm{C}$ to $60^{\circ} \mathrm{C}$, the dissociation of IR $120 \mathrm{~B}$ decreases by a factor of 0.63 , while the radioactivity in the $\mathrm{T}-\mathrm{for}-\mathrm{H}$ exchange reaction becomes 1.7 times. Then, the increasing rate of " $\mathrm{HTO} \rightleftharpoons \mathrm{T}^{+}+\mathrm{OH}^{-}$" is estimated to be $2.7(1.7 \times 1.0 / 0.63)$ if one raises the temperature from $20^{\circ} \mathrm{C}$ to $60^{\circ} \mathrm{C}$.

Thus, the presumption ${ }^{6,8}$ that Formula (2) is more predominant than Formula (1) at high temperature could be quantitatively expressed in this work.

\section{Effect of the matrix of anion-exchange resins on the OT-} for-OH exchange reaction

In order to survey the effect of the matrix of anionexchange resins on the OT-for-OH exchange reaction, IRA458 was used and the results were compared with those of IRA $400 .{ }^{8}$ The radioactivity incorporated into IRA458 by the OT-for-OH exchange reaction is shown in Fig. 4. It is found that the higher the temperature is, the smaller is the radioactivity due to the OT-for-OH exchange reaction in IRA458. The trend is similar to that of IRA $400^{8}$. In addition, the decreasing rate for IRA458 is larger than that for IRA400. In other words, the effect of temperature on the OT-for-OH exchange reaction in acryl type anion-exchange resin is larger than that in styrene type one. This may be attributed to the heat-resistant difference between the two types of resins. The result suggests that the exchange capacity
Table 3 Radioactivity per functional group in IRA96SB $\left(\mathrm{OH}^{-}\right.$-form and $\mathrm{Cl}^{-}$-form $)$at each temperature

\begin{tabular}{|c|c|c|c|}
\hline \multirow{2}{*}{ Temperature $/{ }^{\circ} \mathrm{C}$} & & Total $^{\mathrm{a}}$ & 1,4-Dioxane \\
\hline & & $10^{-18} \mathrm{~Bq}$ & $10^{-18} \mathrm{~Bq}$ \\
\hline \multirow[t]{2}{*}{20} & $\mathrm{OH}^{-}$-form & $1.71 \pm 0.15$ & $0.90 \pm 0.02$ \\
\hline & $\mathrm{Cl}^{-}$-form & $14.50 \pm 0.21$ & $5.49 \pm 0.15$ \\
\hline \multirow[t]{2}{*}{40} & $\mathrm{OH}^{-}$-form & $1.58 \pm 0.11$ & $0.83 \pm 0.05$ \\
\hline & $\mathrm{Cl}^{-}$-form & $12.70 \pm 1.21$ & $4.26 \pm 0.41$ \\
\hline \multirow[t]{2}{*}{60} & $\mathrm{OH}^{-}$-form & $1.49 \pm 0.01$ & $0.75 \pm 0.02$ \\
\hline & $\mathrm{Cl}^{-}$-form & $11.50 \pm 0.67$ & $4.36 \pm 0.34$ \\
\hline \multirow[t]{2}{*}{80} & $\mathrm{OH}^{-}$-form & $1.30 \pm 0.06$ & $0.67 \pm 0.06$ \\
\hline & $\mathrm{Cl}^{-}$-form & $10.60 \pm 0.68$ & $4.36 \pm 0.36$ \\
\hline
\end{tabular}

a. "Radioactivity of $\mathrm{OT}^{-}$due to exchange reaction (or due to the hydrolysis)" + "Radioactivity of HTO adsorbed".

b. "Radioactivity of HTO adsorbed".

for acryl type anion-exchange resin decreases much more rapidly than that for styrene type one with raising the temperature. It can be presumed that the decomposition of the functional group may be gradually caused as the temperature increases.

In order to confirm this, the total ion-exchange capacity for IRA458 $\left(\mathrm{OH}^{-}\right.$-form $)$was measured after heating at $80^{\circ} \mathrm{C}$ for $5 \mathrm{~h}$. A large decrease (about $20 \%$ decrease) of total ion-exchange capacity for the resin was found, but the total ion-exchange capacity was not equal to zero.

Baumann ${ }^{15,16}$ suggested that the decomposition reaction in anion-exchange resin occurs according to a Hoffmann-decomposition of quaternary ammonium base.

$$
\mathrm{R}-\mathrm{CH}_{2}-\mathrm{N}^{+}\left(\mathrm{CH}_{3}\right)_{3} \mathrm{OH}^{-} \longrightarrow \mathrm{R}-\mathrm{CH}_{2} \mathrm{OH}+\mathrm{N}\left(\mathrm{CH}_{3}\right)_{3}
$$

$$
\mathrm{R}-\mathrm{CH}_{2}-\mathrm{N}^{+}\left(\mathrm{CH}_{3}\right)_{3} \mathrm{OH}^{-} \longrightarrow \mathrm{R}^{-} \mathrm{CH}_{2} \mathrm{~N}\left(\mathrm{CH}_{3}\right)_{2}+\mathrm{CH}_{3} \mathrm{OH}(16)
$$

Trimethylamine $\left(\mathrm{N}\left(\mathrm{CH}_{3}\right)_{3}\right)$ has the smell of ammonia, and the aqueous solution shows basic. Accordingly, we suppose that $\mathrm{HCl}$ was neutralized with $\mathrm{N}\left(\mathrm{CH}_{3}\right)_{3}$ produced by Reaction (15) when the ion-exchange capacity of heat-treated IRA458 was measured. In the heattreated operation, trimethylamine ion was detected. Therefore, total ion-exchange capacity was decreased.

Effect of temperature on the reactivity of weakly basic anion-exchange resin

The total radioactivity in IRA96SB $\left(\mathrm{OH}^{-}\right.$-form and $\mathrm{Cl}^{-}$-form) is shown in Table 3. It is found that the total radioactivity in $\mathrm{Cl}^{-}$-form resin is much larger than the radioactivity in $\mathrm{OH}^{-}$-form resin in the case of weakly basic resin.

The radioactivity of $\mathrm{T}$ incorporated as adsorbed water in the resin was estimated by rinsing each dried resin with some organic solvents after the OT-for-OH exchange reaction. Eight organic solvents of ethanol, 1-propanol, 2-propanol, 1-buthanol, 1,4-dioxane, $N, N$ - 


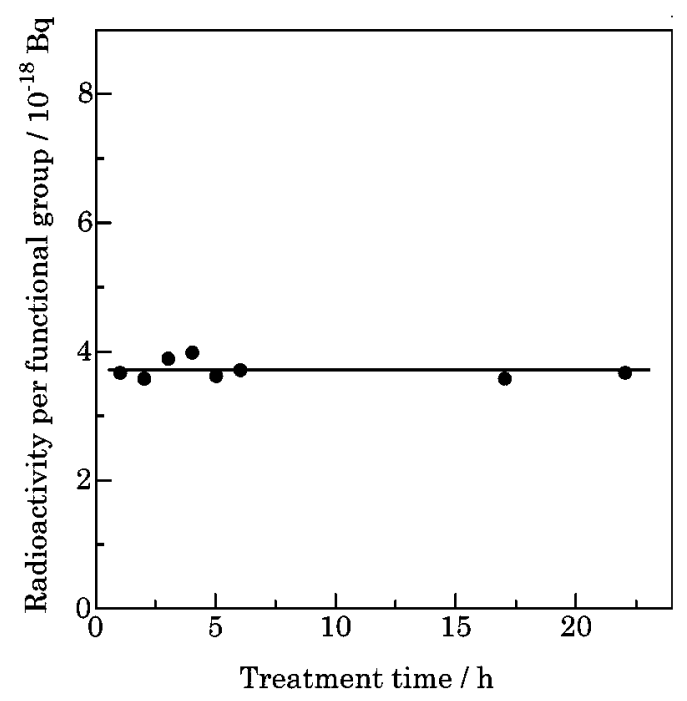

Fig. 5 Radioactivity per functional group in IRA96SB $\left(\mathrm{Cl}^{-}\right.$form) vs. treatment time with 1,4-dioxane. Reaction temp.: $40^{\circ} \mathrm{C}$.

dimethylformamide (DMF), dimethyl sulfoxide (DMSO), and ethylenediamine were used because each of them has a strong affinity for water and is expected not to cause the OT-for-OH exchange reaction in the resins. The radioactivity removed from IRA96SB $\left(\mathrm{Cl}^{-}\right.$ form) by treating with each organic solvent, and that removed with $\mathrm{HCl}$ solution after organic solvent-treatment, were also measured. It is found that the radioactivity rinsed with 1,4-dioxane is the least, and is supposed that the other organic solvents may react with the resin. Ethers such as 1,4-dioxane are generally chemically inert. ${ }^{17}$

In order to confirm whether 1,4-dioxane induces the exchange reaction of $\mathrm{OT}^{-}$with $\mathrm{OH}^{-}$in IRA96SB, the relation between the radioactivity in the $\mathrm{Cl}^{-}$-form resin and treatment time was studied (Fig. 5). The figure shows that the radioactivity in the resin is unvaried with time. Therefore 1,4-dioxane is the most suitable solvent for estimating the radioactivity of $\mathrm{T}$ adsorbed as HTO water in the resin.

By subtracting the radioactivity rinsed with 1,4-dioxane from the total radioactivity in Table 3 , the relation between the real radioactivity of IRA96SB due to the exchange reaction (or due to the hydrolysis) and the temperature is also shown in Fig. 4. Based on the figure, the following four points can be suggested and discussed.

(i) The radioactivity incorporated into the $\mathrm{Cl}^{-}$-form resin is much larger than that into the $\mathrm{OH}^{-}$-form resin in case of IRA96SB. Thus, for IRA96SB, the incorporation of $\mathrm{OT}^{-}$by the hydrolysis is much larger than that by the OT-for-OH exchange reaction.

(ii) The higher the temperature is, the smaller is the amount of radioactivity incorporated into IRA96SB $\left(\mathrm{Cl}^{-}\right.$-form). Related to this result, $\mathrm{OT}^{-}$(and $\mathrm{OH}^{-}$) can be supposed to be incorporated into "the $\mathrm{Cl}^{-}$-form weakly basic anion-exchange resin (RCl)" by the hydrolysis as shown in Formulas (17) - (19).

$$
\begin{aligned}
& \mathrm{RCl} \rightleftharpoons \mathrm{R}^{+}+\mathrm{Cl}^{-} \\
& \mathrm{R}^{+}+\mathrm{HTO} \rightleftharpoons \mathrm{ROT}+\mathrm{H}^{+} \\
& \mathrm{R}^{+}+\mathrm{HTO} \rightleftharpoons \mathrm{ROH}+\mathrm{T}^{+}
\end{aligned}
$$

Here, it can be considered that $\mathrm{OT}^{-}$(and $\mathrm{OH}^{-}$) incorporated by the hydrolysis are based on the dissociation of HTO water. When $\mathrm{OT}^{-}\left(\right.$and $\left.\mathrm{OH}^{-}\right)$are incorporated into the resin by the hydrolysis, the degree of the incorporation of OT- into the resin depends on the rate of the dissociation of HTO water. As described above, Formula (2) is more predominant than Formula (1) at high temperature. Accordingly, it can be considered that the higher the temperature is, the smaller is the amount of $\mathrm{OT}^{-}$incorporated by the hydrolysis of IRA96SB ( $\mathrm{Cl}^{-}$-form).

(iii) The radioactivity incorporated into IRA96SB $\left(\mathrm{OH}^{-}\right.$-form) is $1 / 5$ to $1 / 3$ times the radioactivity into IRA400. ${ }^{8}$ From Table $2, K_{\mathrm{b}}{ }^{\prime}$ for IRA96SB is less than that for IRA400 by a factor of $10^{5}$ at each temperature. Therefore, the radioactivity incorporated into "the weakly basic anion-exchange resin $\left(\mathrm{OH}^{-}\right.$-form)" is smaller than the amount incorporated into the strongly basic one.

(iv) The radioactivity incorporated into IRA96SB $\left(\mathrm{OH}^{-}\right.$-form) is less affected by temperature than the radioactivity incorporated into IRA458 (and IRA $400^{8}$ ).

From this work, both the effects of temperature on the dissociation equilibrium of HTO water and on the reactivity of each anion-exchange resin in the OT-for-OH exchange reaction could be quantitatively revealed. Moreover, the data obtained in this work can be useful for the prevention of T-contamination.

\section{References}

1. A. Trivedi, R. B. Richardson and D. Galeriu, Fusion Technology, 28, 982 (1995).

2. H. Imaizumi, J. Radioanal. Nucl. Chem., Art., 177, 229 (1994).

3. H. Imaizumi, K. Nishiwaki and N. Kano, Radiochim. Acta, 76, 201 (1997).

4. H. Imaizumi and K. Funayama, Bunseki Kagaku, 43, 409 (1994).

5. H. Imaizumi, K. Yamauchi and N. Kano, Radiochim. Acta, 79, 57 (1997).

6. H. Imaizumi, J. Gounome and N. Kano, J. Radioanal. Nucl. Chem., 223(1-2), 23 (1997)

7. N. Kano, M. Nihei and H. Imaizumi, Radioisotopes, 45, 613 (1996).

8. N. Kano, D. Arai and H. Imaizumi, Radiochim. Acta, 79, 195 (1997).

9. M. Honda, H. Kakihana and Y. Yoshino, in "Ion Kokan Jushi (Ion-exchange Resin, in Japanese)”, p. 17, Hirokawa 
Publishing Co., Tokyo, 1973.

10. S. Miyahara, T. Ohmagari and S. Sakai in "Jitsuyo Ion Kokan (Practical Ion-exchange, in Japanese)”, p. 167, Kagaku-kogyosha, Tokyo, 1979.

11. H. Imaizumi, Nippon Kagaku Kaishi, 7, 1075 (1983).

12. D. E. Leyden and A. L. Underwood, J. Phys. Chem., 68, 2093 (1964)

13. T. Seiyama and T. Yamabe, in "Ion Kokan Jushi (Ionexchange Resin, in Japanese)”, p. 45, Nikkan Kogyo Shinbunsha, Tokyo, 1963.

14. R. A. Day and A. L. Underwood (Translated by Y. Torii and T. Koh), "Quantitative Analysis (4th ed.)", p. 102,
Baifukan Co. Inc., Japan, 1982.

15. E. W. Bauman, J. Chem. Eng. Data, 5, 376 (1960).

16. N. Hojo in "Kireto Jushi.Ion Kokan Jushi (Chelate Resin-Ion-exchange Resin, in Japanese)”, p. 167, Kodansha, Tokyo, 1977.

7. S. H. Pine (Translated by Y. Yukawa and T. Mukaiyama), "Organic Chemistry (5th ed.)", p. 70, Hirokawa Publishing Co., Tokyo, 1989.

(Received March 29, 1999)

(Accepted August 19, 1999) 